DOI: 10.20472/IAC.2017.33.039

JUNG JOON LEE

Korea Institute of Industrial Technology, Korea, Republic of

SUNJONG LEE

Korea Institute of Industrial Technology, Korea, Republic of

\title{
THE SIZE EFFECT OF POROUS INORGANIC PARTICLE ON AMMONIA GAS DEODORIZATION FOR DEVELOPMENT OF ECO-FRIENDLY CHEMICAL FOAMING AGENT
}

\begin{abstract}
:
Azodicarbonamide (ADCA) is commonly used as typical chemical foaming agent through thermal decomposition. However, development of eco-friendly chemical foaming agent is acutely required due to ammonia gas generated from ADCA. Furthermore, the market demand is also occurring rapidly by international regulation on human health such as 'REACH'(European super-environment regulation), environmental pollutant emission regulation and increase interest of companies for improving working conditions. Therefore, the size effect of porous inorganic particle on ammonia gas deodorization was studied for development of eco-friendly chemical foaming agent. First, ammonia gas deodorizing effect of the inorganic particle was confirmed over $90 \%$ by test analysis on Korea Far Infrared Association (KFIA). The thermal and morphological properties of the inorganic particle were measured by thermal gravimetric analysis (TGA) and scanning electron microscope (SEM) respectively. Also, the surface area of the inorganic particle was analyzed by Brunauer-Emmett-Teller (BET).

Then after fabrication of foaming body using ADCA foaming agent depending on the content and size of the inorganic particle, the foaming efficiency, whiteness and ammonia gas emission were measured and analyzed by hydrometer, color difference meter and ammonia gas detector tube respectively.
\end{abstract}

\section{Keywords:}

Chemical foaming agent, ammonia gas reduction, porous inorganic particle 